\title{
Local Anaesthetic Epidural Solution for Labour: About Concentrations and Additives
}

\author{
Christian Dualé and Martine Bonnin \\ CHU Clermont-Ferrand, \\ Centre de Pharmacologie Clinique (Inserm CIC 501), \\ Anesthésie-Réanimation-Estaing, \\ France
}

\section{Introduction}

Epidural analgesia can be considered nowadays as the standard technique to relieve pain during labour. Wide information is now available about the different parameters the clinician has to choose to conduct it, namely drugs, concentrations, regimens and additives. The recently published guidelines from the American Society of Anesthesiologists Task Force on Obstetric Anesthesia illustrate the strong improvement of knowledge in this field (ASA Task Force on Obstetric Anesthesia, 2007). Nevertheless, the actual research still focuses on the pathways to increase the efficacy/risk ratio of epidural analgesia.

A first option is to develop local anaesthetics with a hypothetical lower toxicity, thanks to the pharmaceutical companies for this effort. As an example, two amide local anaesthetics produced in the pure levorotatory form - ropivacaine and levobupivacaine - are now available for epidural analgesia in labour, to face the hypothetical risk of toxicity of bupivacaine. The use of ropivacaine has increased in the field of obstetrics in some industrialised countries (Beilin et al., 2007; Sah et al., 2007; Page et al., 2008; Beilin \& Halpern, 2010). Levobupivacaine, the pure S(-)-enantiomer of bupivacaine, recently emerged as a safer alternative for regional anesthesia than its racemic parent (Bardsley et al., 1998; Mather \& Chang, 2001; Burlacu \& Buggy, 2008). In addition to a lower toxicity per se, levobupivacaine has been claimed by some authors to be more potent than bupivacaine (Camorcia \& Capogna, 2003; Sah et al., 2007) or ropivacaine (Benhamou et al., 2003), (Burlacu \& Buggy, 2008), and even to induce less impairment of motricity (Lacassie \& Columb, 2003; Beilin et al., 2007; Lacassie et al., 2007; Sah et al., 2007).

A second option is to lower the concentration of the local anaesthetic solution. This option would somewhat mitigate the problem of bupivacaine toxicity, and may also explain why a superior safety of the two recent molecules is not yet clinically evidenced. The practice of epidural analgesia for labour in our institution - a university hospital of central France in which about 3.500 women deliver yearly - may illustrate this issue. Indeed, the protocols in for induction and maintenance of analgesia the early 80 's used top-up injections of bupivacaine $0.25 \%$, or even more in some cases. Analgesia seemed excellent for most of the parturients, but with this practice raised also questions about side effects, namely 
impairment of motricity and proprioception. Practitioners were therefore questioned by a publication of Chestnut et al. (Chestnut et al., 1988), reporting the interest of an infusion of bupivacaine, i.e. four times less concentrated than in their practice. This highlighted the virtues of the differential nerve block, with a possibility to block selectively the nociceptive pathways (i.e. unmyelinated or few myelinated fibres) without affecting the other components of nerve transmission (Powell et al., 1988; Reid, 1998). Practitioners were therefore encouraged to use a new range of concentrations, from the lowest (i.e. 0.0625 to $0.08 \%$ ), to higher - but reasonable - concentrations (around $0.125 \%$ ). The aim was to strike a difficult balance between the lowest motor block possible (to facilitate labour and vaginal delivery, and even allow ambulation) and an optimal analgesia (Polley et al., 2003; Benhamou et al., 2003; ASA Task Force on Obstetric Anesthesia, 2007; Buyse et al., 2007). Fortunately, the risk of a failure of analgesia with the lowest concentrations could be reduced by the systematic adjunction of epidural opiates (Bernard et al., 2001; Benhamou et al., 2002; Halpern et al., 2003; Lim et al., 2004; ASA Task Force on Obstetric Anesthesia, 2007; Mcleod et al., 2007). Interestingly, it seems that such potentiation by epidural opiates is due to a segmental action, as opiates are able to reduce the minimal local anaesthetic concentration (MLAC) (Polley et al., 1998; Robinson et al., 2001; Ginosar et al., 2003; Buyse et al., 2007).

Since then, it appears that many physicians have reduced the current concentrations in their daily practice. In our hospital for example, a $0.125 \%$-concentration is now the maximal standard for bupivacaine, while ropivacaine and levobupivacaine are preferred by some practitioners. However, it seems that the concentration issue is still incompletely resolved and needs further investigation. This was highlighted in 2007 with two interesting statements of the ASA Task Force (ASA Task Force on Obstetric Anesthesia, 2007):

1. There are no differences in the analgesic efficacy of low concentrated solutions with opiates, compared with higher concentrations without opiates (the cut-off value for concentration being bupivacaine $0.125 \%$ or equivalent). However, it is not known if this level of analgesic efficacy can be considered as optimal, or if it could be improved. Would such equivalence still exist if low concentrated solutions with opiates were compared to higher concentrations with opiates? Is the use of higher concentrations also completely safe, in terms of drug income?

2. The technique to select "should reflect patient needs and preferences, practitioner preferences or skills, and available resources" (ASA Task Force on Obstetric Anesthesia, 2007). Although anyone would agree with this wise recommendation, the issue of preference(s) probably needs clarification. Are there standard - and evidenced-based criteria on which can be determined either the patient's, or the practitioner's preference between two or more techniques?

A good illustration of the issue is the marketing of levobupivacaine in France, which, since July 2005, is available in pre-filled bags (100 or $200 \mathrm{~mL}$ ) with two different concentrations (0.625 and 1.25 mg.mL-1). Both presentations have the same indication, i.e. analgesia in postoperative context and in labour (AFSSAPS, 2011a; AFSSAPS, 2011b). Then, the choice between the two concentrations mostly depends on the practitioner, and this choice appears to depend mostly of his/her personal beliefs, rather than of scientific evidence. Furthermore, the parturient may not be very often implicated in such decision, especially if the respective expected effects of both techniques cannot be clearly described to her. 


\section{Comparing two concentrations, both with opiates}

Our aim was to give an answer to the question of equivalence between a low concentrated solution with opiates, and higher concentrations, also with opiates. We also wanted to keep quite pragmatic conditions, to help the practitioners in their practice. For this, we chose the two presentations of levobupivacaine in pre-filled bags (see above), as our institution was quite familiar with these. We felt the pre-filled bags were very convenient for our protocols of epidural analgesia, as the solution could be used for induction and patient-controlled maintenance, the syringe being refilled without hazardous manipulation.

We planned a randomised, controlled and double-blinded trial (see ClinicalTrials.gov NCT00929682, and (Tixier et al., 2010)).

The aim of the trial was to compare the two available presentations of levobupivacaine, in conditions the closest possible to our daily practice. In one arm, the solution for epidural analgesia was levobupivacaine $0.0625 \%$ (called LC for low concentration), in the other, it was levobupivacaine $0.125 \%$ (called $\mathrm{HC}$ for high concentration). In each $100-\mathrm{mL}$ prefilled bag of solution, $10 \mathrm{~mL}(50 \mu \mathrm{g})$ of sufentanil were added. Opiates were also used in the HC group to assess the effect of concentration, without interaction. The final concentrations of levobupicaine were 0.568 or $1.136 \mathrm{mg} . \mathrm{mL}^{-1}$, with sufentanil $0.45 \mu \mathrm{g} . \mathrm{mL}^{-1}$.

The prepared solutions were used both for the induction and the maintenance of analgesia. Induction of analgesia with an initial volume of $20 \mathrm{~mL}$ of anaesthetic solution, followed by a standardised algorithm of top-up manual injections to achieve analgesia, then by a patientcontrolled regimen with 5-mL self-administered boli in addition to a continuous infusion of $5 \mathrm{~mL} . \mathrm{hr}^{-1}$. Our choice for this regimen was a compromise between efficacy and risks (Ferrante et al., 1994; Lim et al., 2008; Halpern \& Carvalho, 2009). Manual injections were always performed by an anaesthetist, with a separate syringe directly filled from the solution bag, after disinfection of the sites. To refill the syringe of the patient-controlled epidural analgesia (PCEA) device, the solution was drawn from the bag through a parallel line secured by a three-way tap.

The study included women in spontaneous uncomplicated labour, with cervical dilatation $\leq$ $7 \mathrm{~cm}$. We included only primiparous women, because pain during labour is commonly more resistant to relief in this sub-population, so we could sort out a greater effect size, and also to increase homogeneity beneath the sample. We excluded induced labour with the same aim of homogeneity, even if this condition is supposed to increase pain during contractions. Indeed, medical induction of labour was not a frequent practice in our centre, and it was simpler to exclude these patients, rather than to plan a stratified randomisation. We also excluded breech presentation, overweight, multiple pregnancy, preeclampsia, or any fetal abnormality.

The principal objective of the study was to assess the quality of the analgesia provided by the two different concentrations of levobupivacaine. As the protocol chosen associated a PCEA and many levels of rescue administration, we were not expecting to observe a difference in the quality of analgesia, but we hypothesised that greater amounts of solution would be administered in the LC group. However, we kept the quality of analgesia as a secondary endpoint. The sample size was estimated from data we had from a previous trial undertaken in our unit in 59 parturients having had a patient-controlled epidural analgesia 
for labour with $0.125 \%$ bupivacaine plus sufentanil $0.25 \mu \mathrm{g} \cdot \mathrm{mL}^{-1}$ (Vernis et al., 2004). Fiftyseven patients per group were necessary to identify a $25 \%$ difference in the primary endpoint, i.e. the hourly consumption of the analgesic solution in mL.hr-1. This number was reached, with 65 patients in the LC group and 60 in the HC group.

Contrary to our expectations, and this probably due to the PCEA regimen, the quality of analgesia was superior in the HC group. The following table illustrates the size of this effect of superiority, i.e. the percentage of reduction of the mean value for the outcome, from LC to $\mathrm{HC}$. The effect size is here calculated out of the mean values in each group. The $\mathrm{p}$ value was $<0.05$ for all the comparisons of outcomes, between the two groups.

\section{Outcome}

Effect size

Pain score 30 minutes after induction

$-30 \%$

$\mathrm{Nb}$. of observations with pain score $>3 / 10,30$ minutes after induction

$-65 \%$

Pain amount (area under curve) during the first 3 hours after induction

$-23 \%$

Percentage (per patient) of observations with pain score $>3 / 10$

$-46 \%$

Pain score at expulsion

$-48 \%$

Pain score at suture of episiotomy or tear

$-61 \%$

We chose this cut-off level of 3/10 to define the cases of relevant pain, as (i) this value is considered as the superior limit of the definition for mild pain (Breivik et al., 2008), and (ii) satisfaction is usually good to excellent when pain scores stay below this level (Halpern et al., 2003).

Probably because of the regimen of administration chosen, this difference in analgesic efficacy was associated to more self- and medically administered epidural injections in the LC group. This analysis considered only the patients who had vaginal delivery ( $\mathrm{n}=58$ and 49 in the LC and HC group, respectively). The following table illustrates the size of this effect, as previously described.

\section{Outcome}

\section{Effect size}

$\mathrm{Nb}$. of patient-administered boluses $-37 \%$

Required volume of epidural infusion (in $\mathrm{ml}^{-\mathrm{hr}^{-1}}$ ) $-20 \%$

We unfortunately did not assess the patient's satisfaction in this study, believing it was not an outcome easy to interpret. It is therefore difficult to know if the observed difference in the quality of analgesia was relevant, as - for example - the percentage (per patient) of observations with pain score $>3 / 10$ was quite low $(20 \%)$ even in the LC group. This issue led us to reconsider the systematic assessment of the patient's satisfaction for further trials, even if this outcome is rarely studied in the trials about analgesia for labour.

Considering safety, we did not find any difference between the two groups for all the outcomes that could be considered as expected side effects of epidural analgesia for labour, namely motor effects, effects on labour and foetal outcomes. However, this must always been considered with caution, as such small-sample studies are always underpowered to sort out such differences. To improve the power to detect an impairment of normal delivery, 
we created a composite binary outcome defined by the occurrence of one of these two outcomes: a caesarean section or a labour lasting more than $390 \mathrm{~min}$, this cut-off value being the third quartile of the whole duration of labour in the subgroup of parturients with vaginal delivery. The risk for this composite outcome was the same in the two groups (37 and $38 \%$ in the LC and HC group, respectively).

We noted however that in the HC group, the administered dose of levobupivacaine overstepped the French recommendations (12.5 mg.hr-1) in more than $1 / 3$ of the cases (AFSSAPS, 2011a; AFSSAPS, 2011b), while this never occurred in the LC group. This had no clinical consequences, probably because these French limits are much lower than the possibly toxic dose in humans (Burlacu \& Buggy, 2008; Purdue Pharma, 2011).

To summarise, we noted particular points in these results:

1. the low-concentrated solution - even with opiates - provided analgesia of lower quality, although we did not assess the impact on the patients' satisfaction;

2. the low-concentrated solution with added opiates provided an excellent analgesia, but the doses administered were often quite high, although we were not potent enough to assess the real clinical effects of such overdosage.

At this step of our reflexion, we felt that two options appeared to increase the efficacy/risk ratio of epidural analgesia for labour:

1. to develop an intermediate concentration, to which opiates should be added;

2. to make ourselves this solution with an intermediate concentration, with the obvious inconveniences of a hazardous manual intervention and a higher cost;

3. to potentiate the analgesia induced by the low-concentrated solution (plus opiates) by another epidural co-analgesic.

\section{Improving analgesic efficacy of low concentrated solutions}

We orientated our investigation on the third choice, as we felt the opportunity to test clonidine as an additive. Clonidine was a well-known drug in our practice, with a quite old history of perispinal administration, as the first report was in 1987 in France (Racle et al., 1987). This choice was supported by the following arguments:

1. clonidine inhibits nociceptive transmission in spinal cord via $\alpha_{2}$ receptors, and may have in addition local anaesthetic effects (Singelyn et al., 1996; Kroin et al., 2004);

2. it was - at least in France - often used epidurally for labour as single injection, either at the induction of epidural analgesia or as a rescue treatment (Chassard et al., 1996; Landau et al., 2002);

3. the systematic addition of clonidine in the solution used for epidural infusion was known to improve post-operative analgesia in diverse models (Tremlett et al., 1999; Paech et al., 2000; Kayacan et al., 2004; Parker et al., 2007);

4. already two French studies used levobupivacaine $0.0625 \%$ given on PCEA with lowconcentrated clonidine, with promising results (Fontaine et al., 2008; Wallet et al., 2010);

5. we recently evidenced the stability over 24 hours of a solution in which levobupivacaine, sufentanil and clonidine were mixed together (Sautou et al., 2011). 
We then planned a second randomised, controlled and double-blinded trial (see ClinicalTrials.gov NCT00983125, and (Bazin et al., 2011)).

To propose a protocol simple to apply, we thought that adding $150 \mu \mathrm{g}$ of clonidine to the LC solution previously studied, would provide a quality of analgesia close to which was given by the HC solution, without the inconvenience of this latter. The two treatments to be compared were then:

- $\quad$ in one arm, levobupivacaine $0.0625 \%$ plus sufentanil $\left(0.45 \mu \mathrm{g} \cdot \mathrm{ml}^{-1}\right)$ plus $150 \mu \mathrm{g}$ of clonidine,

- $\quad$ in the other arm, the same solution with no clonidine.

The final concentration of clonidine was $1.35 \mu \mathrm{g} \cdot \mathrm{ml}^{-1}$. The control group was then very similar to the LC group in the previous study (Tixier et al., 2010).

The choice of this dose of clonidine was motivated by the two following arguments:

1. a safety issue, as this dose was in the range for which a co-analgesic effect had been found with no increase of side effects (Tremlett et al., 1999; Kayacan et al., 2004; Huang et al., 2007; Fontaine et al., 2008);

2. practical reasons, as it seemed easy to the practitioner to add the full dose of the available presentation of clonidine $(150 \mu \mathrm{g})$ to the prefilled bag of levobupivacaine at the start of epidural analgesia.

The volumes used and the maintenance regimens (PCEA) were similar to those used in the previous study (Tixier et al., 2010). The inclusion and non-inclusion criteria were also the same, except the required cervical dilatation set to $\leq 5 \mathrm{~cm}$. The primary outcome was the total number of additional boluses, i.e. either self-administered or manually administered by the anaesthetist as a rescue.

The sample size estimation was based on the values for the primary outcome that were noted in the previous study (Tixier et al., 2010). As clonidine was not labelled for epidural administration during labour in France, we planned interim analyses, to be able to discontinue the trial in case of safety problems. The initial objective (62 patients per group) was reached (125 patients included), but 10 protocol violations occurred; the effects on the primary outcome were anyway analysed in intent-to-treat.

The superiority of the solution with added clonidine compared to the control was evidenced, for all the outcomes related to the quality of analgesia. Here, we analysed the effects on pain by a linear mixed model, which showed a significant difference $(\mathrm{p}<0.0001$ for the model), with an effect of time and of interaction treatment*time. Furthermore, even satisfaction was greater in the clonidine group $(p=0.0006)$, which is not often noted in such trials. The superiority was also noted for most of the outcomes related to consumption of the epidural solution.

The following table illustrates the size of this effect of superiority, i.e. the percentage of reduction of the mean value for the outcome, from placebo group to clonidine group. The effect size is here calculated out of the mean values in each group. The $p$ value was $<0.05$ for all the comparison of outcomes, between the two groups. 
Considering the hourly administered dose of levobupivacaine, the level recommended by the French label for the drug $\left(12.5 \mathrm{mg}^{\left.-\mathrm{hr}^{-1}\right)}\right.$ was overstepped in only one case, in the placebo group (AFSSAPS, 2011a; AFSSAPS, 2011b).

\section{Outcome}

\section{Effect size}

Pain score 30 minutes after induction

$-37 \%$

$\mathrm{Nb}$. of observations with pain score $>3 / 10,30$ minutes after induction

$-59 \%$

Pain amount (area under curve) during the first 3 hours after induction

$-36 \%$

Percentage (per patient) of observations with pain score $>3 / 10$

$-70 \%$

Pain score at expulsion

$-67 \%$

Pain score at suture of episiotomy or tear

$-52 \%$

$\mathrm{Nb}$. of patient-administered boluses

$-35 \%$

Required volume of epidural infusion (in $\mathrm{ml} . \mathrm{hr}^{-1}$ )

$-15 \%$

Epidural clonidine is likely to induce dose-dependent side effects:

- $\quad$ maternal sedation (O'Meara \& Gin, 1993; Paech et al., 2000; Aveline et al., 2002; Gurses et al., 2003; Roelants et al., 2005);

- maternal hypotension (Chassard et al., 1996; Landau et al., 2002; Aveline et al., 2002; Gurses et al., 2003; Roelants et al., 2005; Parker et al., 2007; Wallet et al., 2010);

- maternal bradycardia (O'Meara \& Gin, 1993; Gurses et al., 2003; Huang et al., 2007);

- abnormalities in foetal heart rhythm (Chassard et al., 1996; Tremlett et al., 1999).

In addition, its intrinsic properties to act as a blocker of nerve transmission (Kroin et al., 2004) could in theory have deleterious effects on labour, as it would be expected with a high-concentrated local anaesthetic agent.

Probably due to the dose chosen, we did not observe serious adverse event in the clonidine group; nevertheless, there was a clear effect of clonidine on maternal blood pressure, uncorrelated to the quality of analgesia. We noted also a highest rate of instrumental delivery in the clonidine group (35 vs. $18 \%, p=0.042$ ). As such pilot studies are underpowered for the infrequently positive outcomes, no conclusion about safety can be given. However, for the composite outcome we created to represent the impairment of

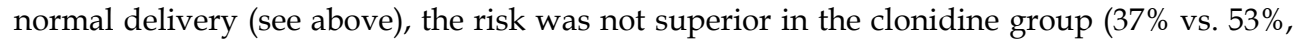
n.s.).

At this stage, it seemed interesting to compare side by side the results of our two studies (four groups), according to the fact that two groups (one from each study) had basically the same analgesic protocol (i.e. levobupivacaine $0.0625 \%+50 \mu \mathrm{g}$ of sufentanil), and the two other groups provided a superior analgesia compared to this protocol. The following table next page helps for this comparison, which remains intentionally descriptive (the values shown are the median). 


\begin{tabular}{|l|c|c|c|c|}
\hline Study & $\begin{array}{c}\text { (Tixier et al., } \\
\text { 2010) }\end{array}$ & $\begin{array}{c}\text { (Bazin et } \\
\text { al., 2011) }\end{array}$ & $\begin{array}{c}\text { (Tixier et } \\
\text { al., 2010) }\end{array}$ & $\begin{array}{c}\text { (Bazin et } \\
\text { al., 2011) }\end{array}$ \\
\hline Concentration of levobupivacaine a & $0.0625 \%$ & $0.0625 \%$ & $0.125 \%$ & $0.0625 \%$ \\
\hline Added sufentanil b & $50 \mu \mathrm{g}$ & $50 \mu \mathrm{g}$ & $50 \mu \mathrm{g}$ & $50 \mu \mathrm{g}$ \\
\hline Added clonidine $\mathrm{b}$ & None & None & None & $150 \mu \mathrm{g}$ \\
\hline Pain after induction c,d & 3 & 3 & 2 & 2 \\
\hline Relevant pain after induction $\mathrm{d}, \mathrm{e}$ & $35 \%$ & $29 \%$ & $14 \%$ & $12 \%$ \\
\hline Pain amount ${ }^{\mathrm{f}}$ & 8.8 & 8.3 & 6.5 & 4.3 \\
\hline Time spent with relevant pain $\mathrm{e}, \mathrm{g}$ & $20 \%$ & $33 \%$ & $11 \%$ & $10 \%$ \\
\hline Pain at expulsion c,h & 3 & 5 & 1 & 0 \\
\hline Pain at suture of episiotomy or tear c,h & 2 & 3 & 0 & 0 \\
\hline $\begin{array}{l}\text { Number of patient-administered } \\
\text { boluses }\end{array}$ & 8.5 & 9 & 6 & 6 \\
\hline Number of rescue injections ${ }^{\mathrm{i}}$ & 0.2 & 0.1 & 0.3 & 0.3 \\
\hline Required volume of epidural infusion $\mathrm{j}$ & 13 & 13 & 10 & 10 \\
\hline
\end{tabular}

Notes: a Initial concentration, i.e. solution in the prefilled bag.

$\mathrm{b}$ Initial full dose, added to the initial solution in the prefilled bag.

c Pain score measured on visual analogue scale (VAS), out of 10.

$\mathrm{d}$ Measured 30 minutes after the induction of the epidural analgesia.

e An observation of relevant pain is an observation of a pain score superior to $3 / 10$ on the visual analogue scale. Here is expressed a rate of positive observations (one per patient) out of the whole group.

$\mathrm{f}$ This is the area under curve for the pain scores measured on VAS, calculated for the first 3 hours after induction according to the trapezoidal rule (Vernis et al., 2004). Patients with missing data (because of early delivery) are excluded.

$\mathrm{g}$ Here is calculated, for each patient, the rate of observations with relevant pain, out of the total number of observations (one per hour throughout labour).

$\mathrm{h}$ I.e. medically administered as a rescue, during maintenance of analgesia. Here are expressed the mean values, all the median values being equal to 0 .

i Expressed in $\mathrm{ml}_{\text {.hr }}{ }^{-1}$.

A systematic addition of clonidine to a low-concentrated solution of local anaesthetic could be therefore a very interesting option, as this may provide the same quality of analgesia than with high-concentrated, but with much lower amounts of anaesthetic given. However, the safety of clonidine is not fully evidenced yet.

\section{New trials to improve our daily practice?}

\subsection{The jungle of variability}

Our results provided interesting information for future research. It would be interesting, for example, to compare a low-concentrated local anaesthetic plus clonidine, with a highconcentrated solution (both having an opiate in addition). 
The encouraging results obtained from these pilot studies may not be sufficient to result in a change of the current practice in obstetrical analgesia. The main reason for this is the small size of these trials, which does not allow concluding, for example, to the full safety of an epidural infusion of a local anaesthetic solution in which clonidine would be added in a systematic way. It is widely accepted that large-sized, pragmatic trials are mandatory to reach a high level of evidence and to influence the medical practice. Such trials are especially tricky to develop in the field of analgesia for labour, because of the huge variability observed at different levels.

Variability in the strategies to rule out epidural analgesia for labour. This is obvious in the published studies, as well as in the current practice of the centres. Multiple elements are to be considered in these strategies, such as:

- the level of puncture;

- the protocol of induction;

- the drug its concentration and the additional opiates (sometimes different for induction and for maintenance);

- $\quad$ the respective roles of the parturient (PCEA...) and the practitioner(s);

- the protocol of maintenance (top-up injections, continuous infusion...)...

Variability in the obstetrical conditions. Three particular conditions are known to increase the intensity of pain during labour, and therefore to reduce the efficacy of analgesic strategies:

- nulliparity,

- medically-induced labour,

- advanced stage of labour.

Variability in the obstetrical practice. The assessment of a new strategy in a validation controlled trial, for example a systematic addition of clonidine to the current epidural solution, would need a sensible assessment of safety outcomes. Some of them, such as motricity, maternal and foetal haemodynamics or sedation level, may be influenced by the new strategy alone. The obstetrical outcomes, such as the duration of labour, the rate of instrumental delivery and the rate of caesarean section, are likely to be also influenced by the obstetrical practice, which varies with the centre, the country, and the year (Ecker \& Frigoletto, Jr., 2007; Sufang et al., 2007). Furthermore, analgesia itself may interact with some of them, as for example a better analgesia may incitate to instrumental delivery.

\subsection{Modelism vs. pragmatism}

Reducing variability by recruiting very homogeneous samples of patients and by standardising the anaesthetic procedures, is a very common method used in clinical research. The main advantage of such methodology is to reach statistical significance with small samples and to quantify effect sizes in very particular situations. However, the results of such studies are unlikely to influence the current practice, as the conditions of the trial may not be considered as realistic to the reader. What would be the effect of clonidine added to bupivacaine administered by top-up injections in multiparous parturients? Furthermore, some of the techniques used (new drugs, PCEA...) are not affordable in many countries. 
In a pragmatic trial, we would accept variability, and this even in the choice of the molecule, as the potency of the three available local anaesthetics may be quite similar (Beilin \& Halpern, 2010). In order to influence the practice worldwide, we would also accept to include patients in several countries, with all the variability in recruitment, obstetrical practice and expectations. This could be faced only by very big sample sizes, to which a stratified randomisation could be applied. The cost of such studies would be extremely high, while only academic institutions would be interested in the promotion of already labelled or even out of patent - drugs.

\subsection{What is the goal of analgesia in labour?}

The gold standard for assessment of pain or analgesia is the quantification of pain on a visual analogue scale, although the numerical rating scale appears to be also a valuable tool (Hjermstad et al., 2011). This is validated in general for the post-operative context. Such outcomes may be however difficult to interpret in the context of labour, in which there may not be a strict linearity between the quality of analgesia and the feelings of the patient about the quality of care. As an example, in a large-sized study comparing epidural bupivacaine and levobupivacaine for labour in nulliparous patients, the patients were asked to quantify the quality of care at the $24^{\text {th }}$ hour after delivery (Halpern et al., 2003). No difference was found between groups in the pains scores during labour. Interestingly, the patients of both groups quantified their feeling of pain relief during labour with values between 66 and $77 / 100$ (76 for the early stage of labour), while the overall satisfaction with pain relief was higher (81/100). Furthermore, the score for the item "overall care met expectations" was even higher (89/100). This discrepancy can be easily explained by a different requirement or a greater indulgence of the patient about the quality of analgesia, to which must be added a cultural tolerance to pain during childbirth (Kloosterman, 1982).

We feel, in our practice, that the particular case of each parturient is not sufficiently considered in current practice of analgesia for labour. This is already well known for the obstetrical context (stage of labour, parity...), although more precise recommendations are still required. The issue of the patient's preferences - as abovementioned (ASA Task Force on Obstetric Anesthesia, 2007) - requires probably a better knowledge of the parturient's expectations and the predictors of her satisfaction about the treatment of labour pain.

\section{Acknowledgement}

We are extremely grateful to our colleagues who took part in the clinical research here mentioned, namely Marie Bazin, Franck Bolandard, Bernard Lavergne, Brigitte Storme, Sébastien Tixier and Lise Vernis, and also to Daniel Bourdeaux and Valérie Sautou (pharmacists) and Bruno Pereira (biostatistician).

\section{References}

AFSSAPS. CHIROCAÏNE $0,625 \mathrm{mg} / \mathrm{ml}$, solution pour perfusion; http://afssapsprd.afssaps.fr/php/ecodex / frames.php?specid=67913100\&typedoc=R\&ref=R0186 626.htm . 2011a. 
AFSSAPS. CHIROCAÏNE $1,25 \mathrm{mg} / \mathrm{ml}$, solution pour perfusion; http://afssapsprd.afssaps.fr/php/ecodex/frames.php?specid=60661814\&typedoc=R\&ref=R0186 627.htm . 2011b.

ASA Task Force on Obstetric Anesthesia (2007). Practice guidelines for obstetric anesthesia: an updated report by the American Society of Anesthesiologists Task Force on Obstetric Anesthesia. Anesthesiology, Vol.106, pp.843-863.

Aveline C., El Metaoua S., Masmoudi A., Boelle P.Y., \& Bonnet F. (2002). The effect of clonidine on the minimum local analgesic concentration of epidural ropivacaine during labor. Anesthesia Analgesia, Vol.95, pp.735-740.

Bardsley H., Gristwood R., Baker H., Watson N., \& Nimmo W. (1998). A comparison of the cardiovascular effects of levobupivacaine and rac-bupivacaine following intravenous administration to healthy volunteers. British Journal of Clinical Pharmacology, Vol.46, pp.245-249.

Bazin M., Bonnin M., Storme B., Bolandard F., Vernis L., Lavergne B., Pereira B., Bazin J.E., \& Dualé C. (2011). Addition of clonidine to a continuous patient-controlled epidural infusion of low-concentration levobupivacaine plus sufentanil in primiparous women during labour. Anaesthesia, Vol.66, pp.769-779.

Beilin Y., Guinn N.R., Bernstein H.H., Zahn J., Hossain S., \& Bodian C.A. (2007). Local anesthetics and mode of delivery: bupivacaine versus ropivacaine versus levobupivacaine. Anesthesia Analgesia, Vol.105, pp.756-763.

Beilin Y., \& Halpern S. (2010). Focused review: ropivacaine versus bupivacaine for epidural labor analgesia. Anesthesia Analgesia, Vol.111, pp.482-487.

Benhamou D., Ghosh C., \& Mercier F.J. (2003). A randomized sequential allocation study to determine the minimum effective analgesic concentration of levobupivacaine and ropivacaine in patients receiving epidural analgesia for labor. Anesthesiology, Vol.99, pp.1383-1386.

Benhamou D., Mercier F.J., Ben Ayed M., \& Auroy Y. (2002). Continuous epidural analgesia with bupivacaine $0.125 \%$ or bupivacaine $0.0625 \%$ plus sufentanil 0.25 microg.mL(1): a study in singleton breech presentation. International Journal of Obstetrical Anesthesia, Vol.11, pp.13-18.

Bernard J.M., Le Roux D., Barthe A., Jourdain O., Vizquel L., \& Michel C. (2001). The doserange effects of sufentanil added to $0.125 \%$ bupivacaine on the quality of patientcontrolled epidural analgesia during labor. Anesthesia Analgesia, Vol.92, pp.184-188.

Breivik H., Borchgrevink P.C., Allen S.M., Rosseland L.A., Romundstad L., Hals E.K., Kvarstein G., \& Stubhaug A. (2008). Assessment of pain. British Journal of Anaesthesia, Vol.101, pp.17-24.

Burlacu C.L., \& Buggy D.J. (2008). Update on local anesthetics: focus on levobupivacaine. Therapeutics and Clinical Risk Management, Vol.4, pp.381-392.

Buyse I., Stockman W., Columb M., Vandermeersch E., \& Van de Velde M. (2007). Effect of sufentanil on minimum local analgesic concentrations of epidural bupivacaine, ropivacaine and levobupivacaine in nullipara in early labour. International Journal of Obstetrical Anesthesia, Vol.16, pp.22-28.

Camorcia M., \& Capogna G. (2003). Epidural levobupivacaine, ropivacaine and bupivacaine in combination with sufentanil in early labour: a randomized trial. European Journal of Anaesthesiology, Vol.20, pp.636-639. 
Chassard D., Mathon L., Dailler F., Golfier F., Tournadre J.P., \& Bouletreau P. (1996). Extradural clonidine combined with sufentanil and $0.0625 \%$ bupivacaine for analgesia in labour. British Journal of Anaesthesia, Vol.77, pp.458-462.

Chestnut D.H., Owen C.L., Bates J.N., Ostman L.G., Choi W.W., \& Geiger M.W. (1988). Continuous infusion epidural analgesia during labor: a randomized, double-blind comparison of $0.0625 \%$ bupivacaine $/ 0.0002 \%$ fentanyl versus $0.125 \%$ bupivacaine. Anesthesiology, Vol.68, pp.754-759.

Ecker J.L., \& Frigoletto F.D., Jr. (2007). Cesarean delivery and the risk-benefit calculus. New England Journal of Medicine, Vol.356, pp.885-888.

Ferrante F.M., Rosinia F.A., Gordon C., \& Datta S. (1994). The role of continuous background infusions in patient-controlled epidural analgesia for labor and delivery. Anesthesia Analgesia, Vol.79, pp.80-84.

Fontaine M.F., Bouvet L., Long Himnam N., Page M., Dale F., Ruynat L., Chassard D., \& Boselli E. (2008). [Intérêt de la clonidine en PCEA obstétricale : étude observationnelle]. Annales Françaises d'Anesthésie et de Réanimation, Vol.27, pp.S150.

Ginosar Y., Columb M.O., Cohen S.E., Mirikatani E., Tingle M.S., Ratner E.F., Angst M.S., \& Riley E.T. (2003). The site of action of epidural fentanyl infusions in the presence of local anesthetics: a minimum local analgesic concentration infusion study in nulliparous labor. Anesthesia Analgesia, Vol.97, pp.1439-1445.

Gurses E., Sungurtekin H., Tomatir E., Balci C., \& Gonullu M. (2003). The addition of droperidol or clonidine to epidural tramadol shortens onset time and increases duration of postoperative analgesia. Canadian Journal of Anaesthesia, Vol.50, pp.147152.

Halpern S.H., Breen T.W., Campbell D.C., Muir H.A., Kronberg J., Nunn R., \& Fick G.H. (2003). A multicenter, randomized, controlled trial comparing bupivacaine with ropivacaine for labor analgesia. Anesthesiology, Vol.98, pp.1431-1435.

Halpern S.H., \& Carvalho B. (2009). Patient-controlled epidural analgesia for labor. Anesthesia Analgesia, Vol.108, pp.921-928.

Hjermstad M.J., Fayers P.M., Haugen D.F., Caraceni A., Hanks G.W., Loge J.H., Fainsinger R., Aass N., \& Kaasa S. (2011). Studies comparing Numerical Rating Scales, Verbal Rating Scales, and Visual Analogue Scales for assessment of pain intensity in adults: a systematic literature review. Journal of Pain and Symptom Management, Vol.41, pp.1073-1093.

Huang Y.S., Lin L.C., Huh B.K., Sheen M.J., Yeh C.C., Wong C.S., \& Wu C.T. (2007). Epidural clonidine for postoperative pain after total knee arthroplasty: a dose-response study. Anesthesia Analgesia, Vol.104, pp.1230-1235.

Kayacan N., Arici G., Karsli B., Bigat Z., \& Akar M. (2004). Patient-controlled epidural analgesia in labour: the addition of fentanyl or clonidine to bupivacaine. Agri, Vol.16, pp.59-66.

Kloosterman G.J. (1982). The universal aspects of childbirth: Human birth as a sociopsychosomatic paradigm. Journal of Psychosomatic Obstetrics and Gynaecology, Vol.1, pp.35-41.

Kroin J.S., Buvanendran A., Beck D.R., Topic J.E., Watts D.E., \& Tuman K.J. (2004). Clonidine prolongation of lidocaine analgesia after sciatic nerve block in rats is mediated via the hyperpolarization-activated cation current, not by alpha-adrenoreceptors. Anesthesiology, Vol.101, pp.488-494. 
Lacassie H.J., \& Columb M.O. (2003). The relative motor blocking potencies of bupivacaine and levobupivacaine in labor. Anesthesia Analgesia, Vol.97, pp.1509-1513.

Lacassie H.J., Habib A.S., Lacassie H.P., \& Columb M.O. (2007). Motor blocking minimum local anesthetic concentrations of bupivacaine, levobupivacaine, and ropivacaine in labor. Regional Anesthesia and Pain Medicine, Vol.32, pp.323-329.

Landau R., Schiffer E., Morales M., Savoldelli G., \& Kern C. (2002). The dose-sparing effect of clonidine added to ropivacaine for labor epidural analgesia. Anesthesia Analgesia, Vol.95, pp.728-734.

Lim Y., Ocampo C.E., Supandji M., Teoh W.H., \& Sia A.T. (2008). A randomized controlled trial of three patient-controlled epidural analgesia regimens for labor. Anesthesia Analgesia, Vol.107, pp.1968-1972.

Lim Y., Sia A.T., \& Ocampo C.E. (2004). Comparison of intrathecal levobupivacaine with and without fentanyl in combined spinal epidural for labor analgesia. Medical Science Monitor, Vol.10, pp.I87-I91.

Mather L.E., \& Chang D.H. (2001). Cardiotoxicity with modern local anaesthetics: is there a safer choice? Drugs, Vol.61, pp.333-342.

Mcleod G.A., Munishankar B., \& Columb M.O. (2007). An isobolographic analysis of diamorphine and levobupivacaine for epidural analgesia in early labour. British Journal of Anaesthesia, Vol.98, pp.497-502.

O'Meara M.E., \& Gin T. (1993). Comparison of $0.125 \%$ bupivacaine with $0.125 \%$ bupivacaine and clonidine as extradural analgesia in the first stage of labour. British Journal of Anaesthesia, Vol.71, pp.651-656.

Paech M.J., Pavy T.J., Orlikowski C.E., \& Evans S.F. (2000). Patient-controlled epidural analgesia in labor: the addition of clonidine to bupivacaine-fentanyl. Regional Anesthesia and Pain Medicine, Vol.25, pp.34-40.

Page J.P., Bonnin M., Bolandard F., Vernis L., Lavergne B., Baud O., Bazin J.E., \& Vendittelli F. (2008). [Epidural analgesia in obstetrics: anaesthesiologists practice in Auvergne]. Annales Françaises d'Anesthésie et de Réanimation, Vol.27, pp.685-693.

Parker R.K., Connelly N.R., Lucas T., Serban S., Pristas R., Berman E., \& Gibson C. (2007). Epidural clonidine added to a bupivacaine infusion increases analgesic duration in labor without adverse maternal or fetal effects. Journal of Anesthesia, Vol.21, pp.142147.

Polley L.S., Columb M.O., Naughton N.N., Wagner D.S., van de Ven C.J., \& Goralski K.H. (2003). Relative analgesic potencies of levobupivacaine and ropivacaine for epidural analgesia in labor. Anesthesiology, Vol.99, pp.1354-1358.

Polley L.S., Columb M.O., Wagner D.S., \& Naughton N.N. (1998). Dose-dependent reduction of the minimum local analgesic concentration of bupivacaine by sufentanil for epidural analgesia in labor. Anesthesiology, Vol.89, pp.626-632.

Powell H.C., Kalichman M.W., Garrett R.S., \& Myers R.R. (1988). Selective vulnerability of unmyelinated fiber Schwann cells in nerves exposed to local anesthetics. Laboratory Investigation, Vol.59, pp.271-280.

Purdue Pharma. Chirocaine Injection. http://www.painhealth.com/medical-product X.asp?i=11516 . 2011.

Racle J.P., Benkhadra A., Poy J.Y., \& Gleizal B. (1987). Prolongation of isobaric bupivacaine spinal anesthesia with epinephrine and clonidine for hip surgery in the elderly. Anesthesia Analgesia, Vol.66, pp.442-446. 
Reid D. (1998). Differential nerve block. Canadian Journal of Anaesthesia, Vol.45, pp.1039-1043.

Robinson A.P., Lyons G.R., Wilson R.C., Gorton H.J., \& Columb M.O. (2001). Levobupivacaine for epidural analgesia in labor: the sparing effect of epidural fentanyl. Anesthesia Analgesia, Vol.92, pp.410-414.

Roelants F., Lavand'homme P.M., \& Mercier-Fuzier V. (2005). Epidural administration of neostigmine and clonidine to induce labor analgesia: evaluation of efficacy and local anesthetic-sparing effect. Anesthesiology, Vol.102, pp.1205-1210.

Sah N., Vallejo M., Phelps A., Finegold H., Mandell G., \& Ramanathan S. (2007). Efficacy of ropivacaine, bupivacaine, and levobupivacaine for labor epidural analgesia. Journal of Clinical Anesthesia, Vol.19, pp.214-217.

Sautou V, Bonnin M, Bourdeau D, Bazin M, Tixier S, Dualé C, Chopineau J, Bazin JE. Etude pharmacologique de stabilité des poches pré-remplies de levobupivacaine avec adjonction de sufentanil et de clonidine. Annales Françaises d'Anesthésie et de Réanimation. 2011 (abstract).

Singelyn F.J., Gouverneur J.M., \& Robert A. (1996). A minimum dose of clonidine added to mepivacaine prolongs the duration of anesthesia and analgesia after axillary brachial plexus block. Anesthesia Analgesia, Vol.83, pp.1046-1050.

Sufang G., Padmadas S.S., Fengmin Z., Brown J.J., \& Stones R.W. (2007). Delivery settings and caesarean section rates in China. Bulletin of the World Health Organization, Vol.85, pp.755-762.

Tixier S., Bonnin M., Bolandard F., Vernis L., Lavergne B., Bazin J.E., \& Dualé C. (2010). Continuous patient-controlled epidural infusion of levobupivacaine plus sufentanil in labouring primiparous women: effects of concentration. Anaesthesia, Vol.65, pp.573-580.

Tremlett M.R., Kelly P.J., Parkins J., Hughes D., \& Redfern N. (1999). Low-dose clonidine infusion during labour. British Journal of Anaesthesia, Vol.83, pp.257-261.

Vernis L., Dualé C., Storme B., Mission J.P., Rol B., \& Schoeffler P. (2004). Perispinal analgesia for labour followed by patient-controlled infusion with bupivacaine and sufentanil: combined spinal-epidural vs. epidural analgesia alone. European Journal of Anaesthesiology, Vol.21, pp.186-192.

Wallet F., Clement H.J., Bouret C., Lopez F., Broisin F., Pignal C., Schoeffler M., Derre E., Charpiat B., Huissoud C., Aubrun F., \& Viale J.P. (2010). Effects of a continuous low-dose clonidine epidural regimen on pain, satisfaction and adverse events during labour: a randomized, double-blind, placebo-controlled trial. European Journal of Anaesthesiology, Vol.27, pp.441-447. 


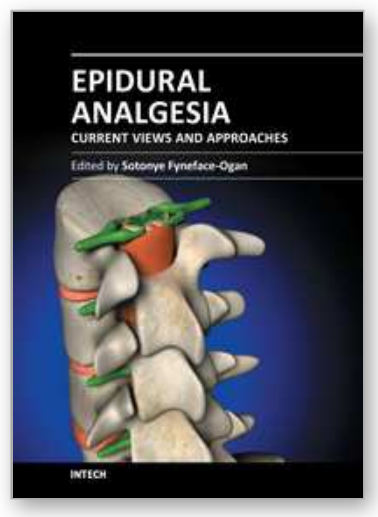

\author{
Epidural Analgesia - Current Views and Approaches \\ Edited by Dr. Sotonye Fyneface-Ogan
}

ISBN 978-953-51-0332-5

Hard cover, 174 pages

Publisher InTech

Published online 16, March, 2012

Published in print edition March, 2012

Epidural analgesia is a form of pain relief administered through the space surrounding the dural sheath either by direct injection or via catheter. The agent, when administered, can cause both a loss of sensation (anesthesia) and a loss of pain (analgesia), by reversibly interrupting the transmission of signals through nerves in or near the spinal cord. This form of pain relief has been found useful in many clinical situations. This book intends to provide an in-depth review of the current knowledge on epidural analgesia. The use of this form of analgesia is explored by contributors from different perspectives, including labor and delivery, postoperative analgesia in both pediatric and geriatric patients, and its role during anesthesia and surgery. In order to provide a balanced medical view this book was edited by an obstetric anesthesiologist.

\title{
How to reference
}

In order to correctly reference this scholarly work, feel free to copy and paste the following:

Christian Dualé and Martine Bonnin (2012). Local Anaesthetic Epidural Solution for Labour: About Concentrations and Additives, Epidural Analgesia - Current Views and Approaches, Dr. Sotonye FynefaceOgan (Ed.), ISBN: 978-953-51-0332-5, InTech, Available from: http://www.intechopen.com/books/epiduralanalgesia-current-views-and-approaches/local-anaesthetic-epidural-solution-for-labour-about-concentrationsand-additives

\section{INTECH}

open science | open minds

\author{
InTech Europe \\ University Campus STeP Ri \\ Slavka Krautzeka 83/A \\ 51000 Rijeka, Croatia \\ Phone: +385 (51) 770447 \\ Fax: +385 (51) 686166 \\ www.intechopen.com
}

\author{
InTech China \\ Unit 405, Office Block, Hotel Equatorial Shanghai \\ No.65, Yan An Road (West), Shanghai, 200040, China \\ 中国上海市延安西路65号上海国际贵都大饭店办公楼 405 单元 \\ Phone: +86-21-62489820 \\ Fax: +86-21-62489821
}


(C) 2012 The Author(s). Licensee IntechOpen. This is an open access article distributed under the terms of the Creative Commons Attribution 3.0 License, which permits unrestricted use, distribution, and reproduction in any medium, provided the original work is properly cited. 